ASTHMA

\title{
Effects of gas and other fume emitting heaters on the development of asthma during childhood
}

\author{
L L Phoa, B G Toelle, K Ng, G B Marks
}

Thorax 2004;59:741-745. doi: 10.1136/thx.2003.014241

See end of article for authors' affiliations

.....................

Correspondence to: Dr G B Marks, Box M77, Missenden Road Post Office, Camperdown NSW 2050, Australia; g.marks@unsw.edu.au

Received 4 August 2003 Accepted 1 March 2004

\begin{abstract}
Background: Several studies have shown adverse effects of gas cookers and heaters on respiratory health. The long term effects of early life exposure to these appliances are not known. This study investigated the effect of exposure to fume emitting heaters, currently and during the first year of life, on the risk of asthma outcomes.

Methods: A cross sectional study of schoolchildren $(n=627)$ aged 8-11 years was conducted in Belmont, Australia. Information on symptoms and heating types was collected by parent completed questionnaire. Atopy was assessed by skin prick tests and airway hyperresponsiveness (AHR) was assessed by histamine challenge test.

Results: There was no association between the current use of fume emitting heaters and any of the asthma outcomes. However, having been exposed to fume emitting heaters during the first year of life was associated with an increased risk of having AHR (relative risk (RR) 1.47, 95\% confidence interval (Cl) 1.06 to 2.03 ), recent wheeze ( $R R 1.44,95 \% \mathrm{Cl} 1.11$ to 1.86 ), and recent wheeze $+\operatorname{AHR}(\operatorname{RR} 2.08,95 \% \mathrm{Cl} 1.31$ to 3.31 ).

Conclusion: If confirmed in other settings, this finding would require a review of the range of heating types that are appropriate for use in households in which young children live.
\end{abstract}

A sthma is the most prevalent chronic disease in childhood $^{12}$ with increasing morbidity in most countries globally, ${ }^{2}$ making it a major public health problem. Epidemiological studies have shown an increasing trend in the prevalence of childhood asthma in different parts of the world. ${ }^{3-7}$ Although environmental factors linked to the aetiology of asthma have not been clearly established, various irritant exposures have been suggested as causative or exacerbating factors. These include environmental tobacco smoke, air pollution, and combustion products from fume emitting appliances as well as indoor and outdoor allergens. ${ }^{8} 9$

The presence of asthma in school age children reflects the cumulative impact of lifelong events and exposures as well as current exposures to such factors. The impact of changes in early life exposure to the microbial environment on the postnatal development of immune functions and consequent predisposition to the development of allergic conditions in childhood is one example of this. ${ }^{10}{ }^{11}$

Another example is the health effects of environmental tobacco smoke exposure in the early years of life, which have been extensively studied. Parental smoking is associated with an increased incidence of acute lower respiratory tract illnesses, including wheezing illnesses in the first 2 years of life, ${ }^{12}$ but no increase in the risk of sensitisation to common aeroallergens. ${ }^{13}$ A systematic review of parental smoking and childhood asthma reported an association of parental smoking with early non-atopic wheezing, which tended to have a benign course. ${ }^{14}$ This suggests that environmental tobacco smoke may be a co-factor provoking wheezing attacks in susceptible individuals, rather than causing the underlying asthmatic tendency. It has also been shown that there is an age related decline in the strength of the association between childhood exposure to environmental tobacco smoke and the presence of asthma. ${ }^{15}$

Indoor air represents an important source of irritant exposures. Time budget studies have shown that people in industrially developed countries spend, on average, $70 \%$ of their time inside the home. Some subpopulations, such as small children and housewives, spend more time indoors than adults in the workforce. ${ }^{8}$ The combustion products of unvented heaters and cookers are an important, potentially adverse, component of indoor air in many homes. Components of such combustion products include nitrogen dioxide $\left(\mathrm{NO}_{2}\right)$, sulphur dioxide, carbon monoxide, particulate matter, and water vapour. ${ }^{16}$ The use of gas appliances leads to higher concentrations of $\mathrm{NO}_{2}$ than is found outdoors, ${ }^{17}$ and this has potential for adverse health effects. ${ }^{18}$

There is conflicting evidence about the adverse health effects of exposure to $\mathrm{NO}_{2} \cdot{ }^{18-20}$ Some epidemiological studies have linked $\mathrm{NO}_{2}$ exposure to an increased prevalence of respiratory symptoms and illnesses. ${ }^{21-24}$ The presence of gas stoves in the household has also been identified as a risk factor for respiratory symptoms in children ${ }^{21}$ and for asthmalike symptoms and reduced lung function in adult women. ${ }^{22}$

As gas heaters without flues are commonly used for domestic heating in New South Wales (NSW), we undertook an investigation of the adverse respiratory health effects of these and other fume emitting heaters. In a general community based population of school children aged 8-11 years we investigated the effect of exposure to fume emitting heaters during the first year of life and currently on the risk of various asthma outcomes.

\section{METHODS}

The analysis presented here was based on data collected in a cross sectional study of primary school children in Belmont, NSW, Australia. The methods used in this study and the findings with respect to the prevalence of asthma have been previously reported..$^{25}$ Details of the methods that are relevant to the analysis conducted for this paper are presented here.

\section{Population samples}

The study population comprised representative samples of primary schoolchildren in Belmont and its surrounding areas. Belmont is a coastal suburb approximately $150 \mathrm{~km}$ north of Sydney and is situated at the southern outskirts of the city of 
Newcastle in NSW, Australia. The Human Ethics Committee of the University of Sydney approved the study. Only children whose parent or legal guardian gave written informed consent were studied.

The study was designed to measure the prevalence of atopy (expected to be approximately $40 \%$ ) with a precision ( $\pm 95 \%$ confidence interval) of $3.5 \%$ and the prevalence of asthma (expected to be approximately $10 \%$ ) with a precision of $2 \%{ }^{25}$ A sample size of 900 children was required and, with an expected response rate of $70 \%$ or greater, we targeted 1300 children for recruitment. The size of the target area was defined to include schools with an aggregate population of 1300 students in years 3, 4 and 5 (age 8-11 years). The sampling frame included all eligible children within the target area except those attending three schools for the disabled and those attending one school with a very small population $(n=42)$ in years 3,4 and 5 . All other schools in the target area were approached and all agreed to participate.

\section{Respiratory symptoms and interviews}

Information on symptoms and diagnoses was collected using parent completed questionnaires. Questions included whether the child had ever had wheeze or had ever had asthma diagnosed by a doctor. Further questions were whether wheezing had occurred in the previous 12 months and if either parent ever had a history of asthma. These questions have previously been tested and shown to have a high degree of repeatability. ${ }^{26}$ A further section in the questionnaire was designed to capture information on the home environment of the children both during their first year of life and currently. The questions in this section included the type of heating used in the home (no heating, central, electric, open fire, reverse cycle, wood stove, gas flued, and gas non-flued or others), the type of cooking appliances used at home (gas, electric/microwave or others), and exposure to home environmental tobacco smoke from maternal smoking (during pregnancy, child's first year of life and currently) and other family members (during child's first year of life and currently). We also asked if the children had ever kept pets at home since birth.

\section{Airway responsiveness (AHR)}

A histamine inhalation challenge test was administered by the rapid method..$^{27}$ Spirometric function was measured using dry rolling seal spirometers (Mijnhardt BV, Bunnik, Holland) connected to a computer (IBM-PC running Scientific and Medical software) for immediate data acquisition. Forced expiratory manoeuvres were repeated until two readings of forced expiratory volume in 1 second $\left(\mathrm{FEV}_{1}\right)$ and forced vital capacity (FVC) within $100 \mathrm{ml}$ were obtained, of which the largest value was used in analyses. Subjects who had taken a short acting $\beta$ agonist within 6 hours or a long acting $\beta$ agonist within 12 hours of presenting were asked to withhold medication before returning for later testing.

Histamine diphosphate was administered in cumulative doses ranging from $0.06 \mu \mathrm{mol}$ to $3.9 \mu \mathrm{mol}$ with hand held nebulisers (De Vilbiss 45, Heston, UK). The test was stopped when the $\mathrm{FEV}_{1}$ fell by $20 \%$ or more from the control level or when the maximum cumulative dose had been administered. Subjects whose $\mathrm{FEV}_{1}$ fell by $20 \%$ or more were classified as having AHR. Subjects who had a baseline $\mathrm{FEV}_{1}$ of less than $60 \%$ predicted were not given histamine but were given $200 \mu \mathrm{g}$ salbutamol. Ten minutes later lung function was measured again. An increase in $\mathrm{FEV}_{1}$ of $15 \%$ or more was taken to be a positive bronchodilator response. These subjects were also classified as having AHR.

Subjects with wheeze in the preceding 12 months were classified as having recent wheeze and those with this and AHR were classified as having current asthma. ${ }^{28}$

\section{Skin prick tests}

Skin prick test reactions to common allergens were measured on the forearm. ${ }^{29}$ The allergens tested were house dust, Dermatophagoides farinae, Dermatophagoides pteronyssinus, ryegrass, cockroach, cat, and Alternaria tenuis (Hollister-Stier, Spokane, WA, USA). Histamine and glycerol were used as positive and negative controls. Wheal size was recorded as the long axis and perpendicular. A mean wheal size of $\geqslant 3 \mathrm{~mm}$ was regarded as positive. Participants were considered to be atopic if they had a positive reaction to any of the seven allergens.

\section{Statistical methods}

The prevalence of subject characteristics, heating types, and other exposures considered to be potential covariates was calculated.

Asthma related outcomes were defined as recent wheeze, AHR, current asthma, doctor-diagnosed asthma, and atopy. Heating types were classified into non-fume emitting and fume emitting types. The non-fume emitting types included central heating, electric heating and reverse cycle heating. The fume emitting types included flued gas, non-flued gas, open fire, wood stove, and kerosene heaters. Subjects who reported having no heating or only non-fume emitting heaters were analysed as being members of the reference category. For the analyses of the effect of fume emitting heaters all subjects who reported using any fume emitting heater were classified as having this exposure (even if they also reported use of non-fume emitting heaters). In a separate series of analyses the effect of ownership of non-flued gas heaters (a subset of fume emitting heaters) was tested. In this analysis subjects without any heating or with only nonfume emitting heaters were the reference category. Subjects with other fume emitting heating types were excluded.

Table 1 Prevalence of subject characteristics, heating types and other exposures

\begin{tabular}{|c|c|c|}
\hline \multicolumn{3}{|c|}{ Prevalence $†$} \\
\hline \multicolumn{3}{|l|}{ Subject characteristics } \\
\hline Recent wheeze & \multicolumn{2}{|l|}{$160(25.9 \%)$} \\
\hline $\begin{array}{l}\mathrm{AHR}\left(\mathrm{PD}_{20} \mathrm{FEV}_{1}\right. \\
<3.9 \mu \mathrm{mol})\end{array}$ & \multicolumn{2}{|l|}{108 (19.3\%) } \\
\hline Current asthma & \multicolumn{2}{|l|}{$62(11.2 \%)$} \\
\hline Diagnosed asthma & \multicolumn{2}{|l|}{$207(33.3 \%)$} \\
\hline Atopy & \multicolumn{2}{|l|}{$216(36.2 \%)$} \\
\hline Male sex & \multicolumn{2}{|l|}{$292(46.7 \%)$} \\
\hline \multirow[t]{2}{*}{ Parental asthma } & \multicolumn{2}{|l|}{$218(38.2 \%)$} \\
\hline & 1st year of life & Current \\
\hline \multicolumn{3}{|l|}{ Heating types* } \\
\hline No heating & $23(3.8 \%)$ & $33(5.3 \%)$ \\
\hline Non-fume emitting: & $409(65.7 \%)$ & $462(73.8 \%)$ \\
\hline Central heating & $46(7.6 \%)$ & $43(6.9 \%)$ \\
\hline Electric heating & $283(46.9 \%)$ & $220(35.1 \%)$ \\
\hline Reverse cycle heating & $89(14.7 \%)$ & $210(33.5 \%)$ \\
\hline Fume emitting: & $242(40.2 \%)$ & $229(36.7 \%)$ \\
\hline Flued gas & $24(4.0 \%)$ & $17(2.7 \%)$ \\
\hline Non-flued gas & $83(13.7 \%)$ & $115(18.3 \%)$ \\
\hline Open fire & $57(9.4 \%)$ & $27(4.3 \%)$ \\
\hline Wood stove & $86(14.2 \%)$ & $72(11.5 \%)$ \\
\hline Kerosene & $8(1.3 \%)$ & $5(0.8 \%)$ \\
\hline \multicolumn{3}{|l|}{ Other exposures } \\
\hline Maternal smoking & $154(26.2 \%)$ & $150(24 \%)$ \\
\hline $\begin{array}{l}\text { Other family members } \\
\text { smoke }\end{array}$ & $114(19.5 \%)$ & $86(13.9 \%)$ \\
\hline Gas cooking & $94(15 \%)$ & $112(17.9 \%)$ \\
\hline Ever kept pets & $528(84.6 \%)$ & \\
\hline \multicolumn{3}{|c|}{$\begin{array}{l}\text { AHR = airway hyperresponsiveness. } \\
\text { *Some participants in the study may have more than one type of heating. } \\
\text { †The denominator population ranges from } 560 \text { to } 627 \text { because of } \\
\text { missing data for some variables. }\end{array}$} \\
\hline
\end{tabular}


Potential covariates tested were atopy, sex, parental asthma, maternal smoking (during pregnancy, during the child's first year of life, and currently), other family members who smoke (during the child's first year of life and currently), gas cooking (during the child's first year of life and currently), and ever having kept pets.

The effect of heating types both in the child's first year of life and currently on each asthma outcome was tested using logistic regression in a two step analysis. In the first stage of the analysis, for each heating type and for each outcome the influential covariates were selected by forward stepwise selection with an entry $p$ value set to 0.1 . In the second phase two fixed models were fitted containing, respectively, exposure to the candidate heating type in the first year of life and current exposure to the candidate heating type, together with the covariates selected from the first phase. In this second phase a log-linear model was fitted (Proc Genmod, log link and binomial error distribution, SAS, SAS Institute, NC, USA) to yield adjusted relative risks and their 95\% confidence intervals for heating types during the child's first year of life and currently.

\section{RESULTS}

The target population for this study was 1222 school children of which 627 (51.3\%) were recruited. The characteristics of the subjects, heating types, and other exposures are shown in table 1 . The prevalence of asthma in this study population has previously been reported. ${ }^{25}$

A substantial minority of children was exposed to fume emitting heaters both in their first year of life and currently. The predominant types of fume emitting heaters were the non-flued gas type (13.7\%) and wood stoves (14.2\%). One quarter of the study population was exposed to maternal smoking during their first year of life and currently (table 1).

We found a strong association between the use of fume emitting heaters during the first year of life and the presence at age 8-11 years of AHR, recent wheeze, and current asthma. However, there was no association between the use of fume emitting heaters during the first year of life and the presence at 8-11 years of either atopy or doctor diagnosed asthma (table 2). The relative risks for asthma related outcomes in the subset of subjects exposed to gas heaters without flues in the first year of life were similar in magnitude to the risks for all subjects exposed to fume emitting heaters (relative risk (RR) 1.36, 1.42 and 1.74 for AHR, recent wheeze and current asthma, respectively). However, only the effect on recent wheeze was statistically significant $(\mathrm{p}=0.04)$ in this analysis.

We did not find any association between current use of fume emitting heaters in the home and any of the asthma outcomes (table 3). The finding was the same when a separate analysis was performed with non-flued gas heaters.

There was no difference between atopic and non-atopic subjects in the effect of fume emitting heater usage in the first year of life on the risk of AHR, recent wheeze, or current asthma ( $p>0.15$ for interaction terms).

\section{DISCUSSION}

This study has shown that there is a strong association between the use of fume emitting heaters (including nonflued gas heaters in a subgroup analysis) during the first year of life and the presence of AHR, recent wheeze, and current asthma in children aged 8-11 years. This effect was not seen with the current use of fume emitting heaters.

The strengths of this study are the use of a broad range of standardised tools for measuring asthma status in childhood and their application in a representative sample of children from the general population. Limitations of the study include the relatively low response rate in the initial survey and the reliance on recall of heating use and other exposures in childhood. Nevertheless, the hypothesis concerning the relation between heating type and asthma risk was not discussed with parents and it is unlikely that differential recall bias is responsible for the observed association between early life exposure to fume emitting heaters and asthma in later childhood. It seems more likely that non-differential misclassification would attenuate the strength of the observed association with early childhood exposures. A further limitation is the absence of objective measures of indoor pollutant exposure, either currently or in the past. Without these data we cannot confidently extrapolate from observations about heating type to conclusions about the effects of specific indoor pollutants.

The most important finding of this study was the observation that early life exposure to fume emitting heaters has effects that are manifest many years later in children age 8-11 years. Without direct measures of specific exposures it not possible to draw conclusions about the specific agents responsible for this effect. Nitrogen dioxide is one of the products of combustion of hydrocarbons that has been shown to have effects on airway mucosa and respiratory health. Although $\mathrm{NO}_{2}$ does not produce significant alterations in airway function of healthy individuals in low concentrations, $^{3031}$ it does induce bronchoconstriction and AHR at higher concentrations. ${ }^{32}$ People with asthma have an increased sensitivity to the effects of $\mathrm{NO}_{2}$, producing similar reactions at lower concentrations..$^{31}{ }^{33}$ Furthermore, $\mathrm{NO}_{2}$ exposure-either alone or in combination with other

\begin{tabular}{|c|c|c|c|}
\hline \multirow[b]{2}{*}{ Asthma outcome } & \multirow{2}{*}{$\begin{array}{l}\text { No fume emitting heaters } \\
\mathrm{N}(\%) \S \S\end{array}$} & \multicolumn{2}{|c|}{ Fume emitting heaters } \\
\hline & & $\mathbf{N}(\%)$ & Relative risk $(95 \% \mathrm{Cl})$ \\
\hline AHR & $64(17.3 \%)$ & $55(25.5 \%)$ & $1.47 \dagger(1.06$ to 2.03$)$ \\
\hline Recent wheeze & $94(23.2 \%)$ & $73(30.5 \%)$ & $1.44 \uparrow \S^{* *}(1.11$ to 1.86$)$ \\
\hline $\begin{array}{l}\text { Current asthma (recent } \\
\text { wheeze }+ \text { AHR) }\end{array}$ & $32(8.7 \%)$ & $37(17.4 \%)$ & $2.08+\ddagger(1.31$ to 3.31$)$ \\
\hline Diagnosed asthma & $138(34 \%)$ & $78(32.2 \%)$ & $0.93 \ddagger^{* *}(0.74$ to 1.17$)$ \\
\hline Atopy & 144 (36.6\%) & $91(40.1 \%)$ & $1.12 \ddagger \ddagger(0.91$ to 1.38$)$ \\
\hline \multicolumn{4}{|c|}{ 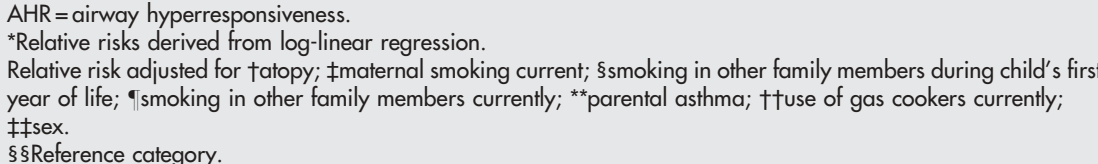 } \\
\hline
\end{tabular}


Table 3 Prevalence of asthma and relative risks* according to current heating types

\begin{tabular}{|c|c|c|c|}
\hline \multirow[b]{2}{*}{ Asthma outcome } & \multirow{2}{*}{$\begin{array}{l}\text { No fume emitting heaters } \\
\mathrm{N}(\%)^{* * *}\end{array}$} & \multicolumn{2}{|c|}{ Fume emitting heaters } \\
\hline & & $\mathrm{N}(\%)$ & Relative risk $(95 \% \mathrm{Cl})$ \\
\hline AHR & 81 (19.4\%) & $43(21.1 \%)$ & $0.88 \dagger \S \S(0.61$ to 1.27$)$ \\
\hline Recent wheeze & $111(24.3 \%)$ & $69(30.4 \%)$ & $1.03+\S^{* *} \S \S(0.77$ to 1.38$)$ \\
\hline $\begin{array}{l}\text { Current asthma (recent } \\
\text { wheeze }+ \text { AHR) }\end{array}$ & $46(11.2 \%)$ & $26(12.9 \%)$ & $0.94 † \ddagger \S \S(0.58$ to 1.54$)$ \\
\hline Diagnosed asthma & 155 (33.7\%) & 75 (32.9\%) & $0.91 \dagger \ddagger^{* *}(0.72$ to 1.14$)$ \\
\hline Atopy & $163(36.7 \%)$ & $76(35.2 \%)$ & $0.97 \neq \ddagger(0.78$ to 1.21$)$ \\
\hline \multicolumn{4}{|c|}{ 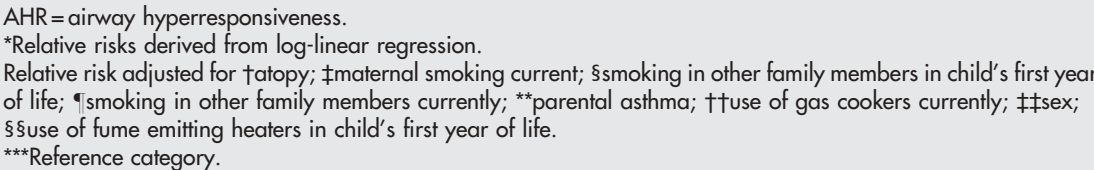 } \\
\hline
\end{tabular}

pollutants such as sulphur dioxide-may potentiate AHR to inhaled allergens such as house dust mite. ${ }^{34-37}$

Other combustion products from fume emitting heaters which have potential for adverse respiratory effects include particulate matter from wood smoke and sulphur dioxide. Wood smoke has been associated with an increased prevalence of cough and wheeze in children living in households using a wood burning stove for heating. ${ }^{38}$ It has also been reported that exposure to wood smoke by children, especially those with asthma, resulted in reduced pulmonary function. ${ }^{39}$ Although sulphur dioxide does cause bronchoconstriction in people with asthma and, as an outdoor pollutant, has been linked to asthma symptoms ${ }^{40}$ and hospital admissions ${ }^{41}$ in some settings, it is unlikely to be responsible for these findings as fossil fuels used in Australia are relatively low in sulphur.

Given the association between heating type used in early childhood and current manifestations of asthma, it is surprising that no associations were observed with current heating type. This appears to reflect the importance of the early life events and exposures in the aetiology of asthma. However, it is also possible that the lack of association is attributable to people with established asthma changing from using fume emitting heaters to non-fume emitting ones in an attempt to reduce the severity of asthma.

An interesting observation in our study is the lack of association between the use of fume emitting heaters during the subjects' first year of life and diagnosed asthma as an outcome. We postulate that asthma symptoms such as recent wheeze, as well as objective measurements of AHR, are better indicators of the presence of asthma than "diagnosed asthma". In the latter group, "diagnosed asthma" may include non-asthma diseases such as viral respiratory tract infections, postnasal drip, bronchitis, and gastro-oesophageal reflux. These disease conditions may produce symptoms mimicking asthma, particularly cough, and hence be misdiagnosed as asthma.

This study has shown that the use of fume emitting heaters in the first year of life is associated with the presence of asthma in later childhood. If confirmed in other settings, this finding would require a review of the range of heating types that are appropriate for use in households in which young children live.

\section{Authors' affiliations}

L L Phoa, B G Toelle, K Ng, G B Marks, Woolcock Institute of Medical Research, University of Sydney, Australia

Funding: Australian Health Management Group and Allen \& Hanburys.

GBM is a Practitioner Fellow of the National Health and Medical Research Council of Australia.

\section{REFERENCES}

1 Boner AL, Martinati LC. Diagnosis of asthma in children and adolescents. Eur Respir Rev 1997;7:3-7.

2 Myers TR. Paediatric asthma epidemiology: incidence, morbidity and mortality. Respir Care Clin North Am 2000;6:1-14.

3 Peat JK, Haby M, Spiker J, et al. Has the prevalence of asthma increased? Results from two population study conducted at a nine year interval in Busselton, Western Australia. BMJ 1992;305:1326-9.

4 Shaw RA, Crahe J, O'Donell TV. Increasing asthma prevalence in rural New Zealand adolescent population: 1975-1989. Arch Dis Child 1990;65:1319-23.

5 Gerden PJ, Mullaly DI, Evans R III. National survey of prevalence of asthma among children in the United States, 1976-1989. Pediatrics 1988;81:1-7.

6 Perdizet S, Neukirch F, Cooreman J. Prevalence of asthma in adolescence in various parts of France and its relationship to respiratory allergy manifestations. Chest 1987:91:104-6S.

7 Aberg N, Hesselmar B, Aberg B, et al. Increase of asthma, allergic rhinitis and eczema in Swedish schoolchildren between 1979 and 1991. Clin Exp Allergy 1995;25:815-9.

8 Brunekreef B. Indoor environment. Eur Respir Mon 2000;15:384-99.

9 Viegi G, Annesi I, Matteelli. Epidemiology of asthma. Eur Respir Mon 2003;23:1-25.

10 Matricardi PM, Bonibi S. High microbial turnover rate preventing atopy: a solution to inconsistencies impinging hygiene hypothesis? Clin Exp Allergy 2000;30:1506-10.

11 Martinez FD, Holt PG. Role of microbial burden in aetiology of allergy and asthma. Lancet 1999;354(Suppl 2):1112-5.

12 Strachan DP, Cook DG. Health effects of passive smoking: 1-Parental smoking and lower respiratory illness in infancy and early childhood. Thorax 1997;52:905-14

13 Strachan DP, Cook DG. Health effects of passive smoking: 5-Parental smoking and allergic sensitisation in children. Thorax 1998;53:117-23.

14 Strachan DP, Cook DG. Health effects of passive smoking: 6-Parental smoking and childhood asthma: longitudinal and case control studies. Thorax 1998;53:204-12

15 Strachan DP, Cook DG. Health effects of passive smoking: 3-Parental smoking and prevalence of respiratory symptoms and asthma in school age children. Thorax 1997;52:1081-94.

16 Traynor GW, Girman JR, Apte MG, et al. Indoor air pollution due to emissions from unvented gas-fired space heaters. J Air Pollut Control Assoc 1985:35:231-7.

17 Spengler JD, Ferris BD, Dockery DW, et al. Sulphur dioxide and nitrogen dioxide levels inside and outside homes and the implications on health effects research. Environ Sci Technol 1979;13:1276-80.

18 Fuhlbrigge A, Weiss S. Domestic gas appliances and lung disease. Thorax 1997;52(Suppl 3):58-62.

19 Samet JM, Marbury MC, Spengler JD. Health effects and sources of indoor air pollution. Part 1. Am Rev Respir Dis 1987;136:1486-508.

20 Chauhan AJ. Gas cooking appliances and indoor pollution. Clin Exp Allergy 1999;29:1009-13.

21 Garrett MH, Hooper MA, Hooper BM, et al. Respiratory symptoms in children and indoor exposure to nitrogen dioxide and gas stoves. Am J Respir Crit Care Med 1998; 158:891-5.

22 Jarvis D, Chinn S, Luczynska C, et al. Association of respiratory symptoms and lung function in young adults with use of domestic gas appliances. Lancet 1996;347:426-31.

23 Pilotto LS, Douglas RM, Attewell RG, et al. Respiratory effects associated with indoor nitrogen dioxide exposure in children. Int J Epidemiol 1997;26:788-96

24 Hasselblad V, Eddy DM, Kotchmar DJ. Synthesis of environmental evidence: nitrogen dioxide epidemiology studies. J Air Waste Manage Assoc 1992:42:662-71.

25 Toelle BG, Ng K, Belousova E, et al. The prevalence of asthma and allergy in schoolchildren in Belmont, Australia: three cross sectional surveys over 20 years. BMJ 2004;328:386-7. 
26 Salome CM, Peat JK, Britton WJ, et al. Bronchial hyperresponsiveness in two populations of Australian schoolchildren I. Relation to respiratory symptoms and diagnosed asthma. Clin Allergy 1987;17:271-81.

27 Yan K, Salome CM, Woolcock AJ. Rapid method for measurement of bronchial responsiveness. Thorax 1983:38:760-5.

28 Toelle BG, Peat JK, Salome CM, et al. Towards a definition of asthma for epidemiology. Am Rev Respir Dis 1992;146:633-7.

29 Pepsy J. Skin testing. Br J Hosp Med 1975;14:412-7.

30 Folinsbee $\mathrm{L}$, Horvath SM, Bedi JF, et al. Effect of $0.62 \mathrm{ppm} \mathrm{NO} 2$ on cardiopulmonary function in young male non-smokers. Environ Res 1978;15:199-205.

31 Bylin G, Hedenstirna G, Linduall T, et al. Ambient nitrogen dioxide concentrations increase bronchial responsiveness in subjects with mild asthma. Eur Respir J 1988;1:606-12.

32 Frank NR, Amdur MO, Worcester J, et al. Effects of acute controlled exposure to $\mathrm{SO}_{2}$ on respiratory mechanics in healthy male adults. J Appl Physiol 1962;7:252-8.

33 Jorres R, Magnussen $\mathrm{H}$. Airways response of asthmatics after 30 minute exposure, at resting ventilation, to $0.25 \mathrm{ppm} \mathrm{NO}_{2}$ or $0.5 \mathrm{ppm} \mathrm{SO}_{2}$. Eur Respir J 1990:3:132-7.

34 Devalia JL, Rusznak C, Herdman MJ, et al. Effect of nitrogen dioxide and sulphur dioxide on airway response of mild asthmatic patients to allergen inhalation. Lancet 1994;344:1668-71.
35 Rusznak C, Devalia JL, Davies RJ. Airway response of asthmatic subjects to inhaled allergen after exposure to pollutants. Thorax 1996;51:1105-8.

36 Tunnicliffe WS, Burge PS, Ayres JG. Effect of domestic concentrations of nitrogen dioxide on airway responses to inhaled allergen in asthmatics patients. Lancet 1994;344:1733-6.

37 Ponsonby AL, Dwyer T, Kemp A, et al. A prospective study of the association between home gas appliance use during infancy and subsequent dust mite sensitisation and lung function in childhood. Clin Exp Allergy 2001:31:1544-52.

38 Honicky RE, Osborne JSd, Akpom CA. Symptoms of respiratory illness in young children and the use of wood-burning stoves for indoor heating Pediatrics 1985;75:587-93.

39 Larson TV, Koenig JQ. Wood smoke: emissions and non cancerous respiratory effects. Annu Rev Public Health 1994;15:133-56.

40 Pikhart H, Bobak M, Gorynski P, et al. Outdoor sulphur dioxide and respiratory symptoms in Czech and Polish school children: a smallarea study (SAVIAH). Small Area Variation in Air Pollution and Health. Int Arch Occup Environ Health 2001;74:574-8.

41 Sunyer J, Atkinson R, Ballester F, et al. Respiratory effects of sulphur dioxide: a hierarchical multicity analysis in the APHEA 2 study. Occup Environ Med 2003;60:E2.

\section{LUNG ALERT}

\section{The role of NIV in post-extubation respiratory failure}

$\Delta$ Esteban A, Frutos-Vivar F, Ferguson ND, et al. Noninvasive positive-pressure ventilation for respiratory failure after extubation. N Engl J Med 2004;350:2452-60.

W hilst non-invasive ventilation (NIV) has an established role in treating acute on chronic respiratory failure, its impact on re-intubation rate following elective extubation and subsequent respiratory failure is unclear. This multicentre, randomised, controlled trial addressed whether use of NIV after discontinuation of mechanical ventilation can decrease mortality (primary outcome) or re-intubation rate (secondary outcome). Patients electively discontinued from mechanical ventilation by agreed criteria were observed for 48 hours. Those developing respiratory failure were randomised to a standardised protocol of NIV (114 patients) or medical treatment (107 patients).

All cause mortality was significantly higher in the NIV group $(25 \% v 14 \%, \mathrm{p}=0.048)$, although re-intubation rates were the same in both groups $(48 \%)$. The number needed to harm was nine patients. On the basis of these results, the trial was stopped early at interim analysis. The increased mortality was confined to those requiring re-intubation, and the time between onset of respiratory failure and re-intubation was significantly higher in the NIV group ( 12 hours $v 2.5$ hours, $p=0.02$ ). A retrospective subgroup analysis of patients with COPD showed lower re-intubation rates with NIV, although the study was neither designed nor powered to look at this specific question.

This study shows that the use of NIV for respiratory failure following extubation increases mortality and has no effect on re-intubation rates. This may be mediated by a delay in time to re-intubation for those patients receiving NIV. Further studies using selected patient groups (e.g. COPD) may yet show a role for NIV in this setting.

N M Rahman

Specialist Registrar, Horton Hospital, Banbury, UK naj_rahman@yahoo.co.uk 